\title{
0 capitalismo pós-1990 e a emergência de novos pólos de poder
}

\author{
Maria Terezinha Dalbem Stropper
}

Doutorada do Programa de Pós-Graduação em Geografia da Universidade Federal do Rio Grande do Sul. E-mail: mtdstropper@yahoo.com.br

Recebido em 01/2012. Aceito para publicação em 04/2012.

Versão online publicada em 17/11/2012 (http://seer.ufrgs.br/paraonde)

\begin{abstract}
Resumo - Este texto versa sobre a configuração do capitalismo pós-1990, associada ao reposicionamento dos EUA no sistema internacional. Nesse sentido, o estudo trabalha com a abordagem de teorias contemporâneas sobre o assunto, como a teoria dos ciclos sistêmicos de acumulação de Giovanni Arrighi, o conceito de acumulação via espoliação de David Harvey, bem como o conceito de poder global de José Luís Fiori. Trata-se de levantamento teórico-bibliográfico, resultante de documentação bibliográfica e discussão cruzada entre os diversos autores. Em síntese, esse estudo visa compreender a dimensão das transformações do capitalismo no pós-Guerra Fria e discute a possibilidade de grandes mudanças nos equilíbrios de poder no mundo. Além disso, essa abordagem ressalta os movimentos questionadores à atual fase do capitalismo financeiro, como o trabalho realizad o pelas ONGs.

Palavras-chave: Capitalismo. Hegemonia. Estados Unidos. Sistema Internacional. ONGs.
\end{abstract}

\section{Introdução}

Este ensaio pretende abordar a configuração do capitalismo pós-1990, associada ao reposicionamento dos EUA no sistema internacional. Neste texto, considera-se a conformação de novos pólos de poder - como China, Brasil, Índia, África do Sul -, que foi sendo delineada após o vácuo deixado pela União Soviética, nos anos de 1990. Discute-se, para tanto, a noção de hegemonia e a possibilidade de grandes mudanças nos equilíbrios de poder e riqueza no mundo. A intenção é tentar compreender a dimensão das transformações e buscar sinalizadores para um devir do mundo capitalista.

Trata-se de temática de grande relevância na contemporaneidade, já que a ampliação dos recursos de poder de países emergentes poderá pesar, decisivamente, no reordenamento do sistema internacional centrado nos Estados Unidos. Inclusive, já se evidencia nitidamente o declínio do poder relativo dos Estados Unidos em relação à ampliação de poder de alguns países emergentes. Vale destacar, no entanto, que esse declínio dos Estados Unidos difere de um colapso do poder americano, pois os EUA mantêm instrumentos de poder decisivos no sistema mundial, como a sua elevada concentração de poder financeiro e militar.

Para a discussão proposta, remete-se a alguns autores que fazem uma análise da crise do capitalismo da década de 1970 e da hegemonia dos Estados Unidos no sistema internacional. Nesse sentido, destaca-se, entre outros, Giovanni Arrighi (2009), com sua teoria dos ciclos sistêmicos de acumulação, bem como o conceito de David Harvey $(2005,2011)$ de acumulação via espoliação ou acumulação por despossessão. Tem-se como referência, ainda, José Luís Fiori $(2004,2008)$, com o conceito de poder global. Busca-se entender as transformações do sistema capitalista associadas às transições de poder, a partir de processos de longa duração (mudanças estruturais), articulados com processos de média e curta duração (mudanças conjunturais).

Ressalta-se, aqui, a premissa de que a reconfiguração de poder e as transformações do capitalismo têm implicações de causa e efeito com vários fatores. As forças internacionais devem ser consideradas em suas múltiplas dimensões, não só econômico-financeiras, mas também socioambientais. Nesse sentido, a discussão ajuda a compreender a emergência de novas forças mundiais, bem como movimentos questionadores à atual fase do capitalismo financeiro, como o trabalho realizado pelas ONGs. Assim, contribui para repensar as forças internacionais que podem intervir no reposicionamento dos EUA para o novo século. 


\section{Capitalismo e Hegemonia}

O fim da Guerra Fria, na década de 1990, solapou as bases de sustentação do sistema internacional, o que resultou em uma desordem mundial. Isso ocorreu, segundo Hobsbawn (1999), porque não havia nada para substituir essas bases e pela falência do projeto dos EUA, baseado em um mundo dominado por uma única superpotência. A crise final da URSS e de seu sistema coincidiu com uma grande crise na economia capitalista, que provocou a estagnação econômica dos países centrais e dos países periféricos. Nesse período, os três gigantes da dívida externa eram o Brasil, México e Argentina. Apenas as economias dos EUA, China e Índia apresentaram crescimento quase contínuo (FIORI, 2004). Contudo, a origem dessa crise remonta à década de 1970 e à estratégia americana de retomar o poder no sistema mundial.

Desde a década de 1970, o sistema interestatal capitalista está passando por uma transição entre a crise do Estado de Bem-Estar Social, assentado no modelo fordista-keynesiano da 2a Revolução Industrial, e a implementação do novo regime de acumulação, desencadeado pelos EUA. A essência desse novo regime é a mundialização de instrumentos financeiros mais sofisticados, associados à nova forma de produção e de consumo, introduzida pela revolução da tecnologia, ciência e informação.

Essas mudanças recentes no funcionamento do capitalismo estão produzindo sérias dificuldades para diversas teorias, que resgatam o processo histórico do capitalismo. Alguns autores, segundo Fiori (2008) afirmam que a crise dos anos 1970 - fim do padrão dólar, crise do petróleo, desregulamentação financeira e a derrota americana no Vietnã -, encerrou a era de ouro do capitalismo e assinalou a crise inicial do poderio americano. Nesse sentido, essa crise lembra o economista Charles Kindleberger (1973), que formulou a teoria dos ciclos hegemônicos, para defender a tese do fim da hegemonia dos Estados Unidos. Essa mesma teoria e a tese da decadência americana reaparecem em vários especialistas, como é o caso de Immanuel Wallerstein $(2000,2009)$, com a sua análise do sistema mundo, e Giovanni Arrighi (2009), com a teoria dos ciclos sistêmicos de acumulação.

Para entender a crise da década de 1970, Kindleberger (1973) realizou um estudo sobre a Grande Depressão dos anos 1930. Concluiu que a Inglaterra, naquele período, não conseguiu mais assumir a responsabilidade de estabilizar a economia mundial, e os Estados Unidos não se dispuseram a assumir o seu lugar. 0 autor parte do pressuposto que o funcionamento da "[...] economia mundial precisa de um país estabilizador e de um só país estabilizador" (KINDLEBERGER, 1973, p. 304). Esse país deve ser capaz de fornecer instrumentos indispensáveis ao funcionamento da economia internacional, como a moeda, defesa do livre comércio e regulação das políticas econômicas. Apenas uma cooperação entre os Estados não seria capaz de estabilizar o sistema econômico mundial, porque ele é inerentemente instável e assimétrico. Além disso, esta liderança sempre foi passageira e obedeceu a uma espécie de ciclo vital: ascensão seguida de declínio, da queda e da substituição do antigo líder por um novo país, que passa a exercer a função de liderança. Desse modo, para Kindleberger, depois da crise americana dos anos 1970, a primazia mundial dos EUA começou a declinar.

$\mathrm{Na}$ análise de Immanuel Wallerstein (2000), o Sistema Mundial Moderno requer a existência de poderes hegemônicos para assegurar a ordem no mundo, mas, não necessariamente de um único país estabilizador. Ressalta que, desde a década de 1970, os EUA perderam esse poder (2012). Nas previsões desse autor, até meados do século XXI, o declínio do poder americano pode provocar a crise final do sistema mundial moderno - economia-mundo capitalista que nasceu na Europa, no longo século XVI. Segundo ele, a nova ordem internacional não será dominada por um país isolado.

Para Wallestein (2012), a crise financeira mundial deste início do século XXI é estrutural e começou com a crise da hegemonia americana na década de 1970. As raízes da crise são muitas, destacando-se a incapacidade de reproduzir o princípio básico do capitalismo, que é a acumulação sistemática do capital. Esse princípio foi muito bem sucedido por 500 anos, mas o capitalismo já não pode sobreviver como sistema. Nessa perspectiva, ele é mais radical que outros autores, como Giovanni Arrighi (2008; 2009), por exemplo.

Wallestein (2012) divide a história da hegemonia americana em três distintos períodos: 0 período de 1945-1970, de 1970-2001, e de 2001 até hoje. 0 período de 1945-1970 é considerado como o período de inquestionável hegemonia dos Estados Unidos, devido a alguns aspectos, como o seu monopólio nuclear e o fato de que a sua economia era a mais eficiente e produtiva do mundo. Também contribuíram, para condição hegemônica, os princípios definidos na criação do acordo de Yalta firmado com a URSS.

O período entre 1970-2001 corresponde ao lento declínio dos Estados Unidos, que deu origem à multipolaridade. Nesse período a quebra do monopólio nuclear era ainda muito recente, houve o declínio da taxa de lucro nas atividades produtivas e verificou-se a aceleração do desemprego. Além disso, registrou-se a expansão da busca de 
lucro, através da especulação financeira, e as reformas passaram a ocorrer por conta do neoliberalismo. Acelerou-se a dívida externa dos países em desenvolvimento e ocorreu o colapso da URSS.

0 período posterior a setembro de 2001 é 0 do declínio precipitado dos Estados Unidos e da efetiva multipolaridade. A posição política, econômica e ideológica dos Estados Unidos tornou-se tênue. A única vantagem parecia ser a sua enorme capacidade militar (força aérea e forças especiais). Após o fracasso dos EUA na invasão do Iraque (forças terrestres), o fim do poder americano tornouse ainda mais evidente.

Arrighi (2009), assim como Wallerstein (2000), defende a tese de que o "sistema mundial moderno" requer a existência de potências hegemônicas para assumir a responsabilidade de manter a ordem política no sistema interestatal e assegurar as condições de crescimento da economia mundial. Desse modo, a concepção de hegemonia, para Arrighi (2009), se diferencia de um poder baseado somente pela dominação. "Um Estado dominante exerce uma função hegemônica quando lidera o sistema de Estados numa direção desejada e, com isso, é percebido como buscando o interesse geral". (ARRIGHI, 2009, p.29). Em suma, o autor ressalta que a sua a ideia vai ao encontro da de Gramsci, que associa o consenso e a liderança moral à força e ao consentimento.

Arrighi (2009) faz um estudo histórico dos ciclos do capitalismo em escala mundial. No seu livro, O Longo Século XX, o autor apresenta quatro ciclos sistêmicos de acumulação (CSA) que abarcam todo o curso do capitalismo. Para definir os CSA, esse autor fundamenta-se em Braudel e utiliza-se do fracionamento da fórmula geral do capital apresentada por Marx (DMD). Essa fórmula, segundo Arrighi (2009, p.6):

[....] pode ser interpretada como retratando não apenas a lógica dos investimentos capitalistas individuais, mas também um padrão reiterado do capitalismo histórico como sistema mundial. 0 aspecto central desse padrão é a alternância de épocas de expansão material (fases DM de acumulação de capital) com fases de renascimento e expansão financeiros (fases MD). Nas fases de expansão material, o capital monetário "coloca em movimento" uma massa crescente de produtos (que inclui a força de trabalho e dádivas da natureza, tudo transformado em mercadoria); nas fases de expansão financeira, uma massa crescente de capital monetário "liberta-se" de sua forma mercadoria, e a acumulação prossegue através de acordos financeiros (como na fórmula abreviada de Marx, DD). Juntas, essas duas épocas, ou fases, constituem um completo ciclo sistêmico de acumulação (DMD).

Em outras palavras, cada CSA apresenta uma fase de expansão material e outra de expansão financeira. A fase inicial de cada ciclo - de expansão material - corresponde à predominância da acumulação de capital, através do investimento produtivo. A fase final de cada ciclo - de expansão financeira - corresponde ao deslocamento do capital do setor produtivo para o setor financeiro. Nesta fase, intensifica-se a competição (interestatal e interempresarial) e os conflitos sociais. A expansão financeira é um sintoma de maturidade de um ciclo sistêmico e o início de sua decadência. Antes de terminar a fase financeira, no entanto, uma nova fase de expansão material se inicia com uma nova liderança, expandindo-se materialmente. Em resumo, cada CSA teve a sua fase de desenvolvimento, sua crise sinalizadora, seu caos sistêmico, seguido de transição sistêmica para um novo ciclo.

Os CSA descrevem, paralelamente, a ascensão e a queda da hegemonia (ciclos de poder) e dos respectivos regimes de acumulação (ciclos de capital). Cada CSA é liderado por nações hegemônicas e se identifica por determinado padrão tecnológico. Os ciclos se superpõem, duram mais de um século e, gradativamente, têm sua duração reduzida. 0 primeiro ciclo foi o das cidades italianas Gênova e Veneza (século XV ao início do XVII); o segundo foi o Holandês (fim do século XVI até meados do XVIII); o terceiro foi o Britânico (meados do século XVIII ao início do XX); e o quarto e atual, o Americano, desde o final do século XIX.

$\mathrm{Na}$ análise que Arrighi (2009) faz do ciclo norte americano, ele aponta as décadas de $1950 \mathrm{e}$ 1960 como o auge da sua fase de expansão material. O desdobramento dessa fase, no entanto, resultou numa retirada maciça do capital monetário do comércio e da produção, e as transações tornaramse essencialmente financeiras. Isso ocorreu entre os anos de 1968 e 1973, quando o sistema de paridades fixas, das principais moedas com o dólar americano e do dólar com o ouro, foi abandonado em favor do sistema de taxas de câmbio flexíveis ou flutuantes. "Como resultado[...], em meados da década de 1970, o volume das transações realizadas no mercado monetário offshore já ultrapassara em muitas vezes o valor do comércio mundial" (ARRIGHI, 2009, p. 309). Desse modo, tem-se o recrudescimento da desregulamentação financeira e um período marcado pela intensa competitividade entre bancos e instituições financeiras ao redor do mundo.

Essa mundialização, conforme Santos (2008), 
é promovida pelas inovações tecnológicas, combinadas com a eficiência e a instantaneidade da informação globalizada. Portanto, a partir daí, o capitalismo entra na atual fase de expansão financeira e de crises financeiras. Estes, conforme Arrighi (2009), são os "sinais" de mudanças no ciclo sistêmico norte-americano.

Nesse sentido, o autor afirma:

\begin{abstract}
A crise eminente do regime norteamericano foi assinalada entre 1968 e 1973, em três esferas distintas e estreitamente relacionadas. Militarmente, o exército norte-americano entrou em dificuldades cada vez mais sérias no Vietnã; financeiramente, o Sistema de Reserva Federal dos Estados Unidos verificou ser difícil e, depois, impossível preservar o modo de emitir e regular o dinheiro mundial estabelecido em Bretton Woods; e, ideologicamente, a cruzada anticomunista do governo norteamericano começou a perder legitimidade no país e no exterior. A crise teve uma deterioração rápida e, em 1973, o governo norte-americano havia recuado em todas as frentes. (ARRIGHI, 2009, p. 310)
\end{abstract}

Desse modo, na análise de Arrighi (2009), a década de 1970 é apontada como a crise sinalizadora do ciclo liderado pelos Estados Unidos. Já a belle époque do regime norte-americano (a era Reagan, ocorrida na década de 1980) e os trunfos recentes do capitalismo norte-americano sobre o comunismo soviético seriam apenas um intervalo ou momento de recuperação, entre a crise sinalizadora e a crise terminal do $4^{\circ}$ c ciclo sistêmico de acumulação. Seja como for, apesar de considerar os fatores militares e ideológicos, a explicação de Arrighi (2009) para a crise atual é essencialmente econômica, pois faz referência a uma crise de supracumulação.

A abordagem de Arrighi (2009) limita-se a prever uma crise da hegemonia americana, não chegando a sinalizar o colapso do poderio daquele país. $\mathrm{O}$ autor mantém-se indefinido sobre o surgimento de uma transição hegemônica, pois considera a supremacia militar e monetária dos EUA. Cabe destacar que, para ele, o fim da hegemonia americana não significa necessariamente o fim do sistema interestatal capitalista. Na sua obra "O longo Século XX", entretanto, Arrighi (2009) apontou o Leste Asiático liderado pelo Japão, como a região que já teria substituído a América do Norte, como centro dinâmico dos processos de acumulação de capital em escala mundial. Essas considerações foram feitas, no contexto dos anos 1990, momento que ainda não havia eclodido a crise asiática e a explosão expansiva da China.
Mais recentemente, no seu estudo "Adam Smith em Pequim", Arrighi (2008) reconhece que os EUA ainda são dominantes devido a sua supremacia militar, mas sem hegemonia. Esse autor argumenta que o ressurgimento econômico e político da Ásia Oriental, agora alavancado pela China, poderá vir a pesar decisivamente nos desdobramentos da crise financeira atual e na desorganização da hegemonia americana. Além disso, considera que um eventual $5^{\circ}$ CSA, liderado pela China, possa ter um caráter mais igualitário em termos sociais, considerando as hegemonias precedentes.

José Luiz Fiori (2008) diverge das teorias em que Wallestein (2000) e Arrighi (2009) sustentam suas projeções de longo prazo, como a hipótese de que o sistema mundial moderno requer a existência de potências hegemônicas sucessivas, para manter a sua ordem política e o bom funcionamento da economia internacional. Em geral, de acordo com Fiori (2008), essa teoria das sucessões hegemônicas não consegue dar conta das contradições, dos processos e dos conflitos existentes entre o país líder e os demais Estados. Mais do que isso, essa teoria tem limitações para compreender que os Estados precisam de um movimento contínuo de competitividade, sendo obrigados a se expandirem permanentemente, para seguirem acumulando poder e riqueza. Portanto, para Fiori (2008), as crises e as guerras não são um anúncio do fim de uma hegemonia ou do próprio sistema mundial moderno - hipótese que é defendida por Wallerstein.

Nesse sentido, conforme Fiori (2008) a crise da década de 1970 não enfraqueceu o poder americano. Mais do que isso, os sinais apontados como declínio dos EUA se transformaram num aumento exponencial do poder americano. A desregulamentação dos bancos se transformou nos anos 1990, na mola mestra do capitalismo financeiro globalizado. Foi à sombra da guerra no Vietnã, que os EUA e a China negociaram a sua parceria estratégica, que contribuiu para o desaparecimento da URSS e o final da Guerra Fria. Ainda, a derrota no Vietnã foi o ponto de partida para a revolução da tecnologia militar - armas aéreas e teleguiadasutilizada na Guerra do Golfo, em 1991.

Neste início do século XXI, Fiori (2008) reconhece que os EUA estão enfrentando uma crise de liderança em tempo breve, mas não significa uma diminuição do seu poder estrutural. 0 autor admite falar em declínio relativo dos EUA em relação à China, por exemplo. Mas, este declínio não significa um colapso do poder econômico e da supremacia militar dos EUA. Assim, Fiori (2008) ressalta que os EUA não têm como (nem interesse em) frear a expansão econômica do leste asiático, 
pois conta com a aliança estratégica com a China para gerir seu "poder global".

Essas divergências com as hipóteses de previsões baseadas nos ciclos hegemônicos levaram Fiori (2008) a interessar-se pelo conceito de "poder global". Esse conceito não equivale à noção de hegemonia. Trata-se de uma análise que privilegia a concorrência (jogo das trocas) e a competição (jogo das guerras), impedindo a estabilização e a paz perpétua do sistema mundial. Sendo assim, ele compara esse sistema com um "universo" em expansão, pois todas as potências são expansivas e lutam pelo poder global. Desse modo, o que existe é uma eterna transformação, provocada pelo poder das guerras, competições e fusões.

Nas previsões de Fiori (2008), neste início de século, o núcleo duro da competição geopolítica será formado pelos EUA, China e Rússia. A China deverá a médio e longo prazo se voltar mais para o mercado interno e buscar maior independência em relação aos EUA. Ela tem se restringido à luta pela hegemonia no leste asiático e regiões do Pacífico. A Rússia retomou o seu potencial econômico e militar e está reconstruindo suas zonas de influência na Europa e na Ásia central confrontando interesses dos EUA nessas regiões. Os EUA se mantêm como potência decisiva e aumenta a cada dia a pressão competitiva entre os Estados.

A Índia aparentemente não apresenta características de uma potência expansiva, provavelmente deverá manter uma estratégia nacional de caráter defensivo. 0 Brasil (e outros países da América do Sul) tem sido um dos grandes fornecedores de commodities, sobretudo para a China. 0 aumento dessa pressão competitiva poderá provocar aumento de conflitos entre os Estados da região e entre eles e os EUA. A África do Sul e o Brasil não possuem uma estratégia internacional expansiva ou um inimigo externo definido. Então, esses dois países deverão se manter como potências regionais relevantes (FIORI, 2008).

Por outro lado, segundo Fiori (2008), a inserção da Índia e da China na África subsaariana está transformando essa região na área de "acumulação primitiva" do capitalismo asiático. Nesse caso, o problema consiste no petróleo. "A China deverá aumentar em $150 \%$ o seu consumo energético, a Índia, em 100\% até 2020." (2008, p.51) Hoje, inclusive, a China é a $2^{\text {a }}$ maior importadora de petróleo do mundo, atrás apenas dos EUA. Essa nova realidade acaba por aproximar China e Índia da Rússia, Irã e Venezuela.

A respeito desta sede de petróleo na China, David Harvey (2005) ressalta que as consequências que isso provoca para as mudanças climáticas e para o preço do petróleo (e os conflitos decorrentes) são potencialmente catastróficas. Considera que hoje esses mecanismos de acumulação desempenham um papel bem mais forte do que no passado. Para discutir essas novas questões, o autor constrói seu conceito de acumulação via espoliação. Este conceito refere-se a esta fase atual do capitalismo, iniciada por volta de 1973. Trata-se de uma adequação ao conceito de acumulação primitiva de Marx porque para esse autor parece estranho qualificar de primitivo ou original um processo em andamento. Nesse sentido, a perspectiva de Harvey significa uma abertura da discussão, pois ele percorre outras áreas do áreas do conhecimento, como a Geografia.

A acumulação de capital por meio da espoliação, na percepção de Harvey (2005; 2011), é uma condição necessária para a sobrevivência do capitalismo. Através da espoliação, as crises de sobreacumulação, inerentes ao próprio sistema, podem ser superadas, pelo menos por algum tempo. A condicionalidade da acumulação por espoliação ajuda a resolver o problema da sobreacumulação de duas maneiras: produção de excedentes e desvalorização dos ativos específicos (capital e trabalho). A primeira acontece quando há apropriação de excedentes produzidos ou ao manipular aquelas condições naturais que permitem a fácil produção de excedente. A segunda ocorre, por exemplo, quando se desvaloriza um ativo em lugar específico, para valorizá-lo em outro momento. Essa política acaba favorecendo os investidores que têm liquidez de capital. Isso foi o que provocou a crise das hipotecas subprime e a perda do controle, nos Estados Unidos, em 2007 e 2008.

Desse modo, entre os exemplos da acumulação via espoliação, em épocas recentes, cabe destacar a tendência a privatizações da água e de utilidades públicas de todo gênero, valorizações fraudulentas de ações, desvio de fundos de pensão e, como já foi dito anteriormente, os empréstimos conhecidos como subprime. Em síntese, o capitalismo das últimas décadas vem paulatinamente aprimorando e aprofundando a tendência de espoliar novos territórios de acumulação, através das políticas de privatização e de financeirização. Além disso, essas políticas foram desencadeadas sob a direção dos Estados Unidos e viabilizadas pelas instituições internacionais, como o Banco Mundial, por exemplo. Contaram com o forte apoio do Estado, não exclusivamente, mas, principalmente, nos países periféricos. Inclusive, segundo Harvey:

Foram criados também mecanismos inteiramente novos de acumulação por espoliação. [...] A biopirataria campeia e a pilhagem 
do estoque mundial de recursos genéticos caminha muito bem em benefício de umas poucas grandes companhias farmacêuticas. A escalada da destruição dos recursos ambientais globais (terra, ar, água) e degradações proliferantes de habitats, que impedem tudo exceto formas capital-intensivas de produção agrícola, também resultaram na mercadificação por atacado da natureza em todas as suas formas. (HARVEY, 2005, p. 123)

Diante disso, uma série de movimentos que rejeitam a acumulação por espoliação foi surgindo ao redor do mundo. 0 primeiro grande protesto popular contra as injustiças do capital internacional ocorreu em 1999, em Seattle, durante a reunião de cúpula da Organização Mundial do Comércio (OMC). Depois de 11 de setembro, em 2001, esses movimentos diminuíram e, de repente, reapareceram numa variedade de lutas impressionante. Mais recentemente, após o início da crise financeira mundial, ocorreu a retomada da rejeição à acumulação por espoliação, sobretudo na Europa e nos EUA.

Nesse sentido, cabe destacar o papel político desempenhado por um vasto número de organizações não governamentais (ONGs), desde os anos 1990. Essas organizações se inserem na crise do Estado Moderno, na transição entre o enfraquecimento do Estado de Bem-Estar Social e a implementação de um novo regime de acumulação, iniciado por volta de 1970. Mais precisamente, voltamse para problemas específicos, como ligados ao trabalho, pobreza e impactos no meio ambiente. As ONGs ambientalistas procuram denunciar o apoio prestado pelo Estado, empresas, organismos internacionais (Banco Mundial, Fundo Monetário Internacional (FMI), em particular, pelos seus estímulos a projetos de construção de hidrelétricas, de gás, petróleo e mineração, por exemplo. Algumas ONGs, contudo, estão implicadas em programas neoliberais, conforme os argumentos apresentados por Harvey:

Em alguns casos, no entanto, elas são ativamente neoliberais, defendendo a privatização de funções do Estado de bem - estar social ou promovendo reformas institucionais para facilitar a integração de populações marginalizadas no mercado (esquemas de microcrédito e microfinanças para populações de baixa renda são um exemplo clássico) (HARVEY, 2011, p. 204)

Harvey (2011) admite importantes conquistas das ONGs em certas áreas, como nos direitos da mulher, na saúde e na preservação ambiental. Ele afirma, contudo que, "[...] a mudança revolucionária a partir das ONGs é impossível. Elas são muito limitadas pelas instâncias políticas e de formulação de políticas de seus mantenedores" (HARVEY, 2011, p. 204). Por outro lado, esse autor reconhece o poder coletivo preponderante das ONGs no Fórum Social Mundial, para tentar forjar um movimento de justiça global de alternativa ao neoliberalismo. Desse modo, acredita-se que os movimentos questionadores, na fase atual do capitalismo (como o realizado pelas ONGs), ajudam a pensar as questões discutidas neste texto.

Como já foi dito anteriormente, desde a última década do século XX, os EUA não têm conseguido manter a ordem política no sistema internacional, bem como o crescimento da economia mundial. Assim, desde que invadiram o Iraque (2003) sem o consentimento da ONU, "Os Estados Unidos desistiram da hegemonia pelo consenso e recorrem cada vez mais ao domínio pela coerção" (HARVEY, 2005, p. 162). Para Harvey (2005), as ações dos EUA representam uma posição mais de fraqueza econômica e política do que de força, e a aventura no Iraque pode muito bem assinalar o final da hegemonia dos EUA, em detrimento de uma nova fase de domínio norte-americano. 0 autor ressalta, contudo, as vantagens tecnológicas centradas no complexo industrial-militar dos EUA.

No livro 0 Enigma do Capital, Harvey (2011) analisa o papel das crises, como o da crise atual, na reprodução do capitalismo e os riscos sistêmicos de longo prazo, que o capital representa para o meio ambiente. Segundo ele, a crise mundial atual é a mais profunda desde 1930. Inclusive, deve ser vista como o auge de um padrão de centenas de crises financeiras que ocorreram ao redor do mundo, desde 1973. Muitas dessas crises também estavam associadas aos excessos no mercado imobiliário. Harvey (2011) ressalta que o capitalismo nunca consegue resolver suas crises em definitivo, simplesmente as contorna, movendo-as constantemente de um lugar para outro e de um problema para outro.

A crise econômico-financeira, iniciada em 2007, principalmente no mercado imobiliário dos EUA (juntamente com os do Reino Unido, Irlanda e Espanha), se propagou de uma esfera para outra e produziu efeitos de longa duração em diversos países do mundo, como as crises da dívida da Grécia e da Irlanda. $\mathrm{O}$ efeito tem sido os Estados protegerem e salvarem os bancos, e não os proprietários dos imóveis que perderam suas casas. Em outras palavras, os Estados resgatam as dívidas dos bancos e repassam os custos para o povo (HARVEY, 2011).

Nesse sentido, o socorro bancário atual, apesar de maior, repete a história que ocorreu 
durante a crise da dívida que abalou o México, em 1982. Nesse caso, o FMI e o tesouro dos EUA resgataram as dívidas que o México havia contraído com bancos de Nova York e impuseram medidas de austeridade, que provocaram uma queda de $25 \%$ no padrão de vida dos mexicanos. No caso da Grécia e da Irlanda, a austeridade agravou a situação da dívida e das condições de vida nesses países. Esse assalto ao bem-estar social das massas, em benefício do grande capital, provocou revoltas, como os crescentes sinais de agitação social, verificados na Europa (HARVEY, 2011).

A política da austeridade aplicada na Europa e na América do Norte não é, contudo, praticada em toda parte. O Leste Asiático, centrado na China, a Índia e a América Latina (destacadamente o Brasil), seguem uma estratégia expansionista keynesiana, com o fortalecimento do trabalho e o combate à desigualdade social. Além disso, a China emergiu da crise de maneira mais rápida e com mais sucesso do que qualquer outro país. Esse crescimento da China, no entanto, provoca o rápido aumento da procura por matérias-primas e enormes consequências ambientais (não apenas para a China), com todos os conflitos que podem advir (HARVEY, 2011).

Apesar das inúmeras vulnerabilidades, a China ficou mais protegida da crise mundial atual, segundo Harvey (2011), porque não havia integrado completamente seu sistema financeiro à rede global. Por fim, o autor sinaliza a possibilidade de novas forças mundiais provocarem grande mudança nos equilíbrios de poder. Nesse sentido, acredita que o crescimento explosivo de curto prazo das economias emergentes, do Leste e Sul Asiático e da América Latina, pode ajudar a reequilibrar o poder e a riqueza no sistema mundial. Ainda, Para Harvey (2005), o fortalecimento das relações Sul-Sul, através de alianças entre Brasil, Índia, África do Sul e China, poderá redesenhar a geografia econômica do século XXI, segundo linhas bem mais justas do que as atuais.

\section{Considerações Finais}

Refletir sobre a configuração do capitalismo pós-1990, associada ao reposicionamento dos EUA no sistema internacional, implica transitar por diversas teorias e marcantes acontecimentos do final do século XX e início do século XXI. Está em jogo a força desses acontecimentos na redefinição do capitalismo e no reordenamento do poder internacional. 0 recorte teórico abordado contribui para tentar explicar a aceleração das mudanças, a partir do fim da Guerra Fria.
Nas análises de Arrighi $(2008 ; 2009)$ e de Wallerstein (2012), fica evidente que o declínio do poder americano é um processo que remete à crise dos anos 1970 - fim do padrão dólar, derrota dos EUA no Vietnã, choques do petróleo, desregulamentação financeira. Neste aspecto, Fiori (2008) diverge completamente desses autores, pois considera que esses sinais apontados como declínio se transformaram em fatores do aumento exponencial do poder americano. Já desde o início do século XXI, contudo, Fiori (2008) admite que os EUA estão apresentando um declínio do seu poder em relação à ascensão de alguns Estados, mas isso não significa um colapso do seu poder, nem o fim da sua supremacia mundial.

A hipótese que mais afasta Fiori (2008) das teorias de Arrighi (2009) e de Wallerstein (2000) é a do papel estabilizador das potências hegemônicas sucessivas no sistema mundial, pois considera que os Estados precisam da competição e das guerras para continuar acumulando poder e riqueza. 0 que existe é uma eterna transformação, já que os Estados são tanto ameaçados quanto fortalecidos pelos EUA. Desse modo, se tudo gira em torno de guerra e competição, fica difícil identificar padrões de dominação, a partir do pensamento de Fiori.

As abordagens de Arrighi (2008; 2009) e de Harvey $(2005 ; 2011)$ permitem prever uma crise da hegemonia americana, não chegando a sinalizar o fim dos EUA, muito menos o fim do sistema inter-estatal capitalista. As projeções de longo prazo, sustentadas por Arrighi, ampliam a compreensão do processo de transição sistêmica, como o declínio do poder relativo dos EUA em relação à ampliação dos recursos de poder de países emergentes (principalmente a China), mas ainda não evidenciam nitidamente o final da 4 o CSA liderado pelos EUA. A análise de Harvey sobre o papel dos movimentos insurgentes contra a espoliação (como o realizado pelas ONGs) contribui para repensar essas questões, não só pela dimensão política e econômica, mas também pelo que o autor denomina como socioambiental.

Após a aventura no Iraque e o início da crise financeira atual, esses autores, incluindo Fiori (2008), admitem a abertura de possibilidades para que novos países consigam subir na hierarquia internacional. Nesse sentido, a China representa o mais sério desafio para os EUA, pois concentra recursos de poder inéditos nas três últimas décadas, como o dinamismo econômico-tecnológico e a unidade político-militar. Além disso, o fortalecimento das relações Sul-Sul, através da aliança de potências regionais como Brasil, Índia e África do Sul, pode ter papel decisivo nos desdobramentos 
da crise financeira mundial, iniciada em 2007, nos EUA, e no reordenamento de poder dos EUA no sistema internacional.

\section{Referências}

ARRIGHI, Giovanni. O longo século XX. Rio de Janeiro: Contraponto e São Paulo: Editora UNESP, 2009.

Adam Smith em Pequim: Origens e Fundamentos do século XXI. Boitempo, 2008.

FIORI, José. L. Formação, expansão e limites do poder global. In: FIORI, José L. (Orgs). 0 poder americano. Petrópolis: Vozes, 2004.p.11 a 64.

. O sistema interestatal capitalista no início do século XXI. In: FIORI, José L., MEDEIROS, Carlos e SERRANO, Franklin. 0 mito do colapso do poder americano. Rio de Janeiro: Record, 2008. p. 11 a 70.
HARVEY, David. 0 novo imperialismo. 2.ed. São Paulo: Loyola, 2005.

. 0 enigma do capital e as crises do capitalismo. São Paulo: Boitempo, 2011.

HOBSBAWM, ERIC. Era dos Extremos. 2.ed.São Paulo:Schwarcz,1999.

KINDLEBERGER, C. The World in Depression. Berkeley: University of California Press, 1973.

SANTOS, Milton. Por uma outra globalização. 17 ed. Rio de Janeiro: Record, 2008.

WALLERSTEIN, Imamanuel. The essential Wallerstein. New York: The New Press, 2000.

Declínio Acentuado: o Advento da Multipolaridade. Disponível em: http://pt.scribd.com/ doc/67458287/DECLINIO-ACENTUADO-O-ADVENTODA-MULTIPOLARIDADE. Acesso em: 14 fev. 2012.

\title{
Capitalism post - 1990 and the emergence of new poles of power
}

\begin{abstract}
This article examines capitalism's configuration after 1990, associated to US repositioning within the international system. Therefore, it works with contemporary theoretical approaches on the matter, such as Giovanni Arrighi's theory of Systemic Cycles of Accumulation, David Harvey's concept of accumulation by dispossession, as well as José Luís Fiori's concept of global power. It is a theoreticalbibliographical survey resulting from bibliography documentation and crosscut discussion among several authors. In sum, this study seeks to understand the dimension of changes in post-Cold War capitalism and discusses the possibility of major power balance shifts in the world. Furthermore, the approach underscores movements challenging the current financial capitalism stage, such as that conducted by NGOs.
\end{abstract}

Keywords: Capitalism. Hegemony. United States. International System. NGOs. 